\title{
Comparative Analysis of the Mechanical Properties of Polymer Matrix Composites Reinforced with Fiberglass Fabric
}

\author{
Daniela Spasova, Yaroslav Argiro, Tatyana Mechkarova \\ Technical University of Varna, "Studentska” Str. 1, Varna, Bulgaria
}

\begin{abstract}
The composites materials are increasingly displacing the traditional ones and are the most widely used of all groups of engineering materials. Polymer matrix composites have the greatest application and they are used for equipment operating in the sea-water environment and polymer pipes. In this article, the mechanical properties of six types of polymer matrix composites reinforced with fiberglass fabric are considered and analyzed. Two types of resin were used for the matrix - polyester resin and vinyl ester resin. The both types of matrices are reinforced with three different fiberglass fabric- monoaxial, biaxial and triaxial fiberglass. The investigated composites are obtained by mechanical pressing in the form of sixlayer panels. A comparative analysis of tensile strength and banding strength of the six types investigated composites was made. A macrofractographic analysis of the structure was also performed.
\end{abstract}

Keywords - Polymer matrix composites, polyester resin, vinyl ester resin, fiberglass, marine environment.

\section{Introduction}

The development and application of polymer matrix composite materials (PMC) in the modern industry are very dynamic.

DOI: 10.18421/TEM104-35

https://doi.org/10.18421/TEM104-35

Corresponding author: Daniela Spasova,

Technical University of Varna, "Studentska" Str. 1, Varna,

Bulgaria.

Email: danielats@tu-varna.bg

Received: 16 September 2021.

Revised: 21 October 2021.

Accepted: 29 October 2021.

Published: 26 November 2021.

(cc)BY-NC-ND (C) 2021 Daniela Spasova, Yaroslav Argiro \& Tatyana Mechkarova; published by UIKTEN. This work is licensed under the Creative Commons AttributionNonCommercial-NoDerivs 4.0 License.

The article is published with Open Access at www.temjournal.com
The composite materials successfully replace the steel and aluminium alloys materials, and they are a more cost-effective solution featuring similar properties. The main advantage is that for identical overall dimensions, they are much more lightweight. The fiber-reinforced (PMC) feature good corrosion, chemical resistance, high wear resistance, high specific strength and stiffness, and are thus widely applied in aircraft structures, well as automotive constructions, facilities operating in the sea-water environments, leisure goods and sports [1].

In this paper PMC reinforced with various types of fiberglass fabrics are discussed. One of the applications of this type of composite refers to the manufacturing of pipes and tubular structures. Fiberglass reinforced polymer pipe are excellent substitute of conventional materials like steel, ductile iron and concrete. They have very good strength, corrosion resistance, light weight, they are easy to operate and install, and they have a long-life cycle, which exceeds 30 years. Another advantage of the fiberglass reinforced pipes is that it has a smoother inner surface than traditional materials which prevent large-scale deposits and ensure a higher flow rate, which reduces power consumption [2].

This type of composite material is appropriate for building facilities working in a sea-water environment. One of the study objectives is the selection of a more appropriate material for the manufacturing of a hydrological and meteorological buoy for marine research, which also consists of tubular elements (Figure 1). This dedicated wavemetering buoy will measure, record and transmit real-time wave direction data and full wave spectrum [3], [4]. A distinctive feature of the equipment used in underwater research is that it should have great sensitivity so as to accurately register the studied objects. At the same time, it should be made of materials resistant to marine conditions, especially if it needs to be used all year round. The materials used should not affect the readings or the studied objects [5]. 


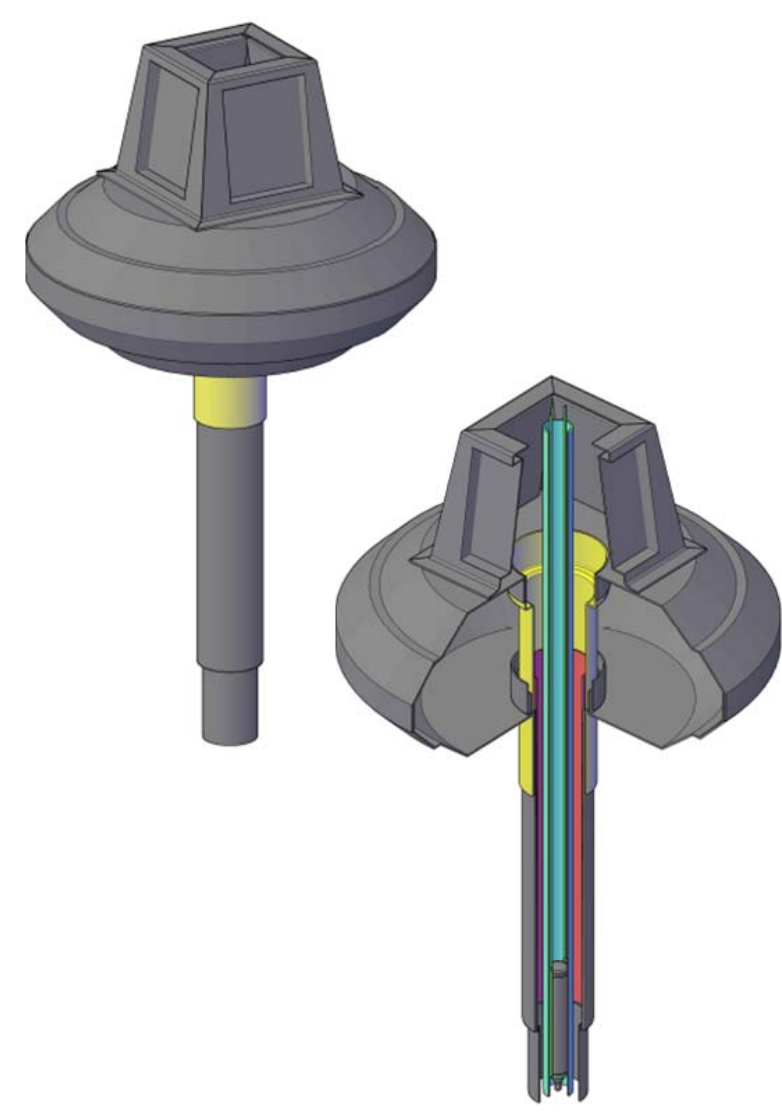

Figure 1. 3D model of dedicated wave- metering buoy

The composite materials used for the production of fiberglass reinforced pipe and various facilities operating in marine environments is composed of a thermosetting polymer matrix, such as epoxy resin, polyester resin or vinyl ester resin. The reinforced fiberglass fibers can be randomly placed, pressed into a sheet or woven into a fabric. Unlike metallic materials, the resin softens the substance and allows its tight application on surfaces of complex geometry. These composites are produced with nearnet shapes of the reinforcement phase in order to increase their mechanical properties. However, the fluid pressure, i.e. seawater pressure brought about the greatest decline of the flexural and tensile strengths of the composites [6].

Therefore, the purpose of this study is to conduct a comparative analysis of the strength of the different types of composites, and to select the most suitable alternative which will be used for the production of the dedicated metering buoy. Six types of fiberreinforced PMC are studied - three types with polyester resin "C-L FH- 123 B" matrix and three types with vinyl ester resin "SIRESTER VE 45M90 AT" matrix. Both types of matrices are strengthened with three different fiberglass fabric- monoaxial 600 $\mathrm{g} / \mathrm{m}^{2}$, biaxial $600 \mathrm{~g} / \mathrm{m}^{2}$ and thriaxial fiberglass 600 $\mathrm{g} / \mathrm{m}^{2}$. Fiberglass mat $450 \mathrm{~g}$ E-glass (chopped strand mat) is inserted between the three layers of fiberglass fabric in order to prevent the fabric from slipping during the composite production. The composites thus obtained feature six reinforcement phase layers, starting with the fiberglass mat. Fiberglass mat (nonwoven fiberglass fabric) is composed of cut glass thread, which is then emulsion (or powder) bonded in a mat. The monoaxial Fiberglass fabric is a glass reinforcement in which the fiber is oriented in one direction. Biaxial fiberglass fabric is composed of glass fibers that are intertwined on top of each other at an angle of $+/-45^{\circ}$ and the $+45^{\circ}$ and $-45^{\circ}$ layers are of identical weight. The triaxial fiberglass fabric $\left(0,+/-45^{\circ}\right)$ feature is a combination of the benefits of unidirectional oriented fibers and biaxial oriented fibers $+/-45^{\circ}$. The fiber tows are at right angles to increase strength and decrease both torsional and longitudinal flexion and strain. All fabrics are coated with Silane for easier wetting out, and is compatible with polyester, vinyl ester and epoxy resin systems [7].

\section{Experimental Procedure}

The composites studied are made in the form of 6 mm-thick panels, by layer-by-layer resin and reinforcement phase application. After applying every consecutive resin layer, air bubbles are removed through mechanical impact, i.e., rolling. [7]. The combinations of a matrix and a reinforcement phase in the investigated composites are presented in Table 1.

Table 1. The combinations of a matrix and a reinforcement phase in the tested composites

\begin{tabular}{|c|c|c|}
\hline $\begin{array}{c}\text { Specimen } \\
\text { № }\end{array}$ & Matrix material & $\begin{array}{c}\text { Reinforcement } \\
\text { material }\end{array}$ \\
\hline 1 & Polyester resin & $\begin{array}{c}\text { 3 layers monoaxial } \\
\text { fiberglass and 3 layers } \\
\text { fiberglass mat }\end{array}$ \\
\hline 2 & Vinyl ester resin & $\begin{array}{c}\text { 3 layers monoaxial } \\
\text { fiberglass and 3 layers } \\
\text { fiberglass mat }\end{array}$ \\
\hline 3 & Polyester resin & $\begin{array}{c}\text { 3 layers biaxial } \\
\text { fiberglass and 3 layers } \\
\text { fiberglass mat }\end{array}$ \\
\hline 4 & Vinyl ester resin & $\begin{array}{c}\text { 3 layers biaxial } \\
\text { fiberglass and 3 layers } \\
\text { fiberglass mat }\end{array}$ \\
\hline 5 & Polyester resin & $\begin{array}{c}\text { 3 layers triaxial } \\
\text { fiberglass and 3 layers } \\
\text { fiberglass mat }\end{array}$ \\
\hline 6 & Vinyl ester resin & $\begin{array}{c}\text { 3 layers triaxial } \\
\text { fiberglass and 3 layers } \\
\text { fiberglass mat }\end{array}$ \\
\hline
\end{tabular}




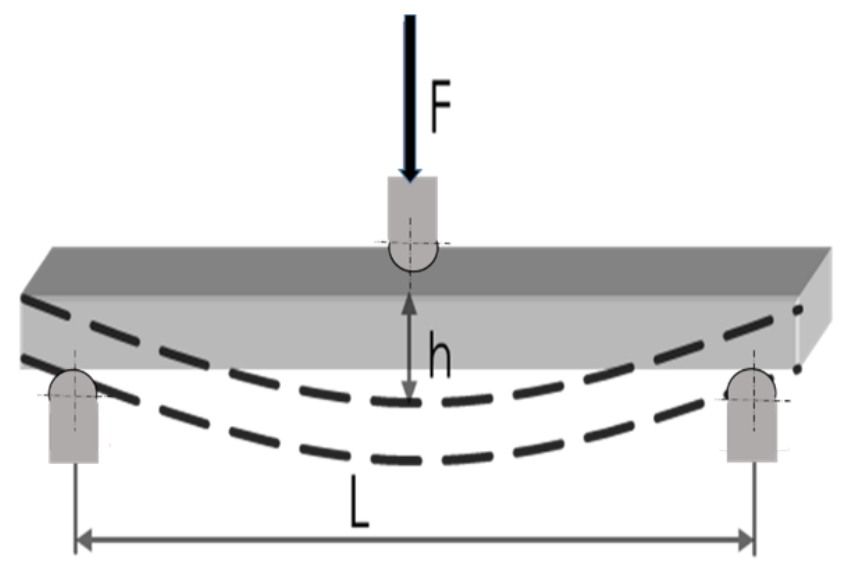

Figure 3. Three-point bending test

Samples for tensile strength and bending tests are cut from the panels produced using this method. After the test is completed, the fracture surface of the tensile test samples was a macro-fractographically analyzed by means of a EUROMEX stereomicroscope.

\section{Tensile Testing}

The tensile test was conformed with ISO 5275:2009 — "Determination of tensile properties Part 5: Test conditions for unidirectional fiberreinforced plastic composites" standard at $\mathrm{T}=20^{\circ} \mathrm{C}$ [8]. The tensile test of the panels obtained of each type of composite are carried out using three samples cut along the length of the reinforcing fiber and three samples cut at an angle of $90^{\circ}$ (transversely). All samples are identical-size and are visible in Figure 2.

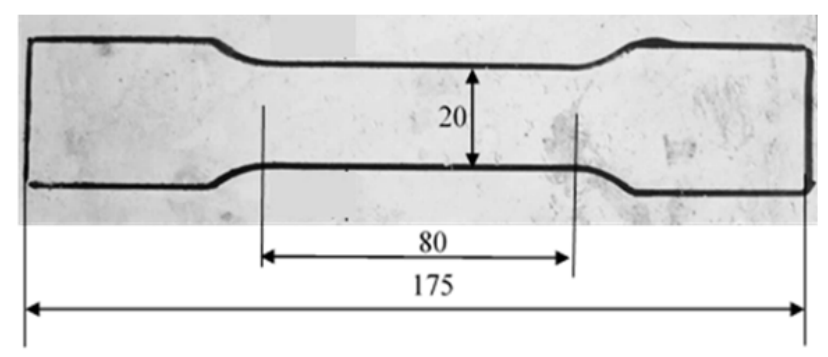

Figure 2. The form and sizes of the tensile testing samples

\section{Bending Testing}

The bending test was conducted according to ASTM D7264 / D7264M - 21 Standard - "Test Method for Flexural Properties of Polymer Matrix Composite Materials" standard - three- point loading configuration with fixed supports and loading nose at $\mathrm{T}=20{ }^{\circ} \mathrm{C}$ (Figure 3) [9], [10]. The bending strength again was determined through cutting three samples along the length of the reinforcing fiber and three samples cut at an angle of $90^{\circ}$ (transversely). The dimensions of the samples are $160 \mathrm{~mm} / 25 \mathrm{~mm}$ and they are cut for each type of composite. The support span length $L$ is $80 \mathrm{~mm}$.

The bending strength of the studied materials is calculated using the formula below:

$$
R_{m b}=\frac{3 F L}{2 b d^{2}}[M P a]
$$

Where: F- load force, $\mathrm{N}$; $L$ - the support span length, $\mathrm{mm} ; b$ - the sample width, $\mathrm{mm}$; $d$ - the sample thickness, $\mathrm{mm}$;

During the bending test, flexural deformation is indicated by the vertical displacement $(h, \mathrm{~mm})$ determined at maximum bending load.

\section{Results and Analyzing}

In Table 2 the obtained results of tensile test are shown and Figure 4 graphically illustrates the average values. Generally, the tensile strength results for vinyl ester matrix composites are slightly higher (around 10\%) than that of polyester matrix composites. Contrary to the preliminary expectations, the monoaxial fiberglass reinforced composites showed the highest tensile strength (310-325 MPa) in both types of the matrix regardless of the angle of orientation of the fibers of the reinforcing phase. Biaxial fiberglass and Triaxial Fiberglass reinforced composites have approximately $30 \%$ lower tensile strength. Triaxial Fiberglass reinforced composites were expected to have the highest tensile strength values, because the triaxial fiberglass fabric feature a combination of the benefits of unidirectional oriented fibers and biaxial oriented fibers $+/-45^{\circ}$.

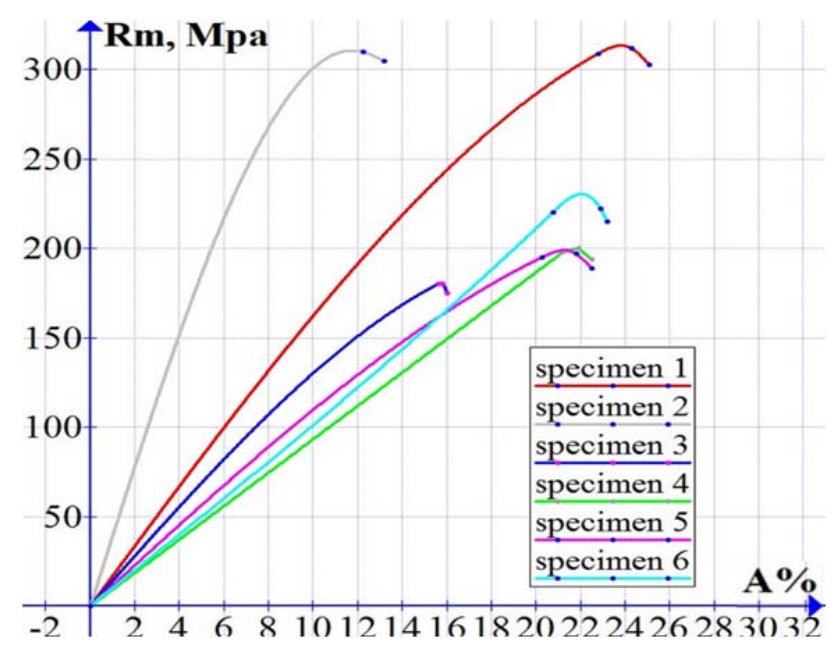

Figure 4. The tensile test average values diagram of the studied composites 
Table 2. The obtained tensile test results

\begin{tabular}{|c|c|c|c|c|}
\hline Specimen & № & Cutting method & $\underset{\text { (MPa) }}{\mathbf{R m}}$ & $\begin{array}{c}\text { Average } \\
\text { value of } \\
\text { Rm } \\
\text { (MPa) }\end{array}$ \\
\hline \multirow{6}{*}{1} & 1 & along the length & 298 & \multirow{6}{*}{310} \\
\hline & 2 & along the length & 301 & \\
\hline & 3 & along the length & 317 & \\
\hline & 4 & an angle of $90^{\circ}$ & 309 & \\
\hline & 5 & an angle of $90^{\circ}$ & 303 & \\
\hline & 6 & an angle of $90^{\circ}$ & 315 & \\
\hline \multirow{6}{*}{2} & 1 & along the length & 315 & \multirow{6}{*}{325} \\
\hline & 2 & along the length & 318 & \\
\hline & 3 & along the length & 337 & \\
\hline & 4 & an angle of $90^{\circ}$ & 318 & \\
\hline & 5 & an angle of $90^{\circ}$ & 323 & \\
\hline & 6 & an angle of $90^{\circ}$ & 332 & \\
\hline \multirow{6}{*}{3} & 1 & along the length & 175 & \multirow{6}{*}{180} \\
\hline & 2 & along the length & 181 & \\
\hline & 3 & along the length & 184 & \\
\hline & 4 & an angle of $90^{\circ}$ & 171 & \\
\hline & 5 & an angle of $90^{\circ}$ & 179 & \\
\hline & 6 & an angle of $90^{\circ}$ & 187 & \\
\hline \multirow{6}{*}{4} & 1 & along the length & 194 & \multirow{6}{*}{200} \\
\hline & 2 & along the length & 199 & \\
\hline & 3 & along the length & 206 & \\
\hline & 4 & an angle of $90^{\circ}$ & 189 & \\
\hline & 5 & an angle of $90^{\circ}$ & 203 & \\
\hline & 6 & an angle of $90^{\circ}$ & 205 & \\
\hline \multirow{6}{*}{5} & 1 & along the length & 193 & \multirow{6}{*}{198} \\
\hline & 2 & along the length & 197 & \\
\hline & 3 & along the length & 202 & \\
\hline & 4 & an angle of $90^{\circ}$ & 198 & \\
\hline & 5 & an angle of $90^{\circ}$ & 200 & \\
\hline & 6 & an angle of $90^{\circ}$ & 203 & \\
\hline \multirow{6}{*}{6} & 1 & along the length & 214 & \multirow{6}{*}{220} \\
\hline & 2 & along the length & 219 & \\
\hline & 3 & along the length & 224 & \\
\hline & 4 & an angle of $90^{\circ}$ & 217 & \\
\hline & 5 & an angle of $90^{\circ}$ & 221 & \\
\hline & 6 & an angle of $90^{\circ}$ & 223 & \\
\hline
\end{tabular}

From the macrostructural fractographic analysis conducted (Figure 5) it can be seen that biaxial reinforced PMC and triaxial reinforced PMC show tangential crack propagation, unlike monoaxial reinforced PMC (Figure 5, a), which is characterized by linear crack propagation, perpendicular to the direction of application of tensile load. Tangential crack development is typically associated with the destruction of brittle materials with lower strength. With monoaxial reinforced PMC, the sample is destroyed after the rupture of the fiberglass fibers (the reinforcing phase). On the other hand, in the case of biaxial and triaxial reinforced PMC, the resin (matrix) is destroyed first, before the fibers of the reinforcing phase are torn since they are intertwined at an angle and under load, they are displaced prior to breakage. This fact explains the lower tensile strength obtained for biaxial and triaxial reinforced PMC. Slightly higher values are obtained for triaxial reinforced composites as compared to biaxial reinforced composites, because the reinforcing fibers are combined from unidirectional and biaxial fiberglass fabric. The unidirectional fiberglass fabric side shows linear crack propagation, perpendicular to the tensile load (Figure 5, c), and in this side of the composite, where the fibers are biaxial, the crack propagation is tangential (Figure 5, d).

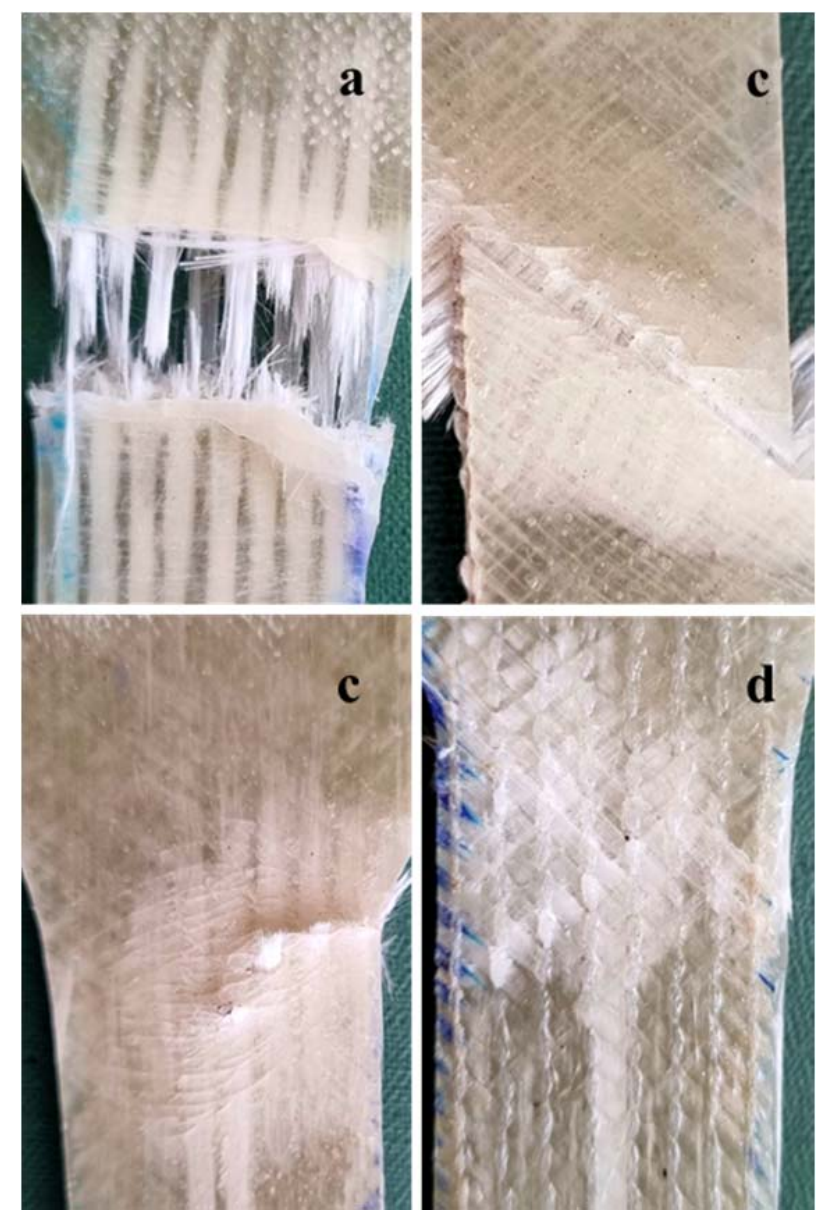

Figure 5. Macrostructure of: a- crack propagation of the monoaxial reinforced PMC; $b$ - crack propagation of the biaxial reinforced PMC; c-crack propagation of the triaxial reinforced PMC from the unidirectional fiberglass fabric side; $d$ - crack propagation of the triaxial reinforced PMC from the biaxial fiberglass fabric side

Table 3 shows the obtained results of banding test and Figure 6 graphically illustrates the average values. The bending strength determined for vinyl ester matrix composites exceed those of polyester matrix composites, with a considerable difference in this case - approximately $60-80 \%$ more except biaxial reinforced composites. 


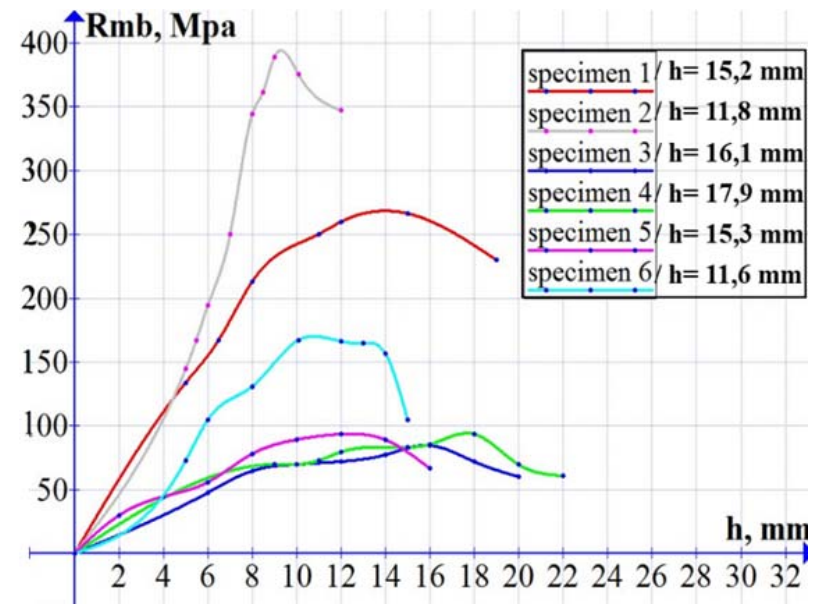

Figure 6. The banding test average values diagram of the studied composites

Table 3. The obtained bending test results

\begin{tabular}{|c|c|c|c|c|}
\hline Specimen & № & Cutting method & $\begin{array}{c}\text { Rmb } \\
\text { (MPa) }\end{array}$ & $\begin{array}{c}\text { Average } \\
\text { value of } \\
\text { Rmb } \\
\text { (MPa) }\end{array}$ \\
\hline \multirow{6}{*}{1} & 1 & along the length & 259 & \multirow{6}{*}{265} \\
\hline & 2 & along the length & 267 & \\
\hline & 3 & along the length & 270 & \\
\hline & 4 & an angle of $90^{\circ}$ & 257 & \\
\hline & 5 & an angle of $90^{\circ}$ & 269 & \\
\hline & 6 & an angle of $90^{\circ}$ & 269 & \\
\hline \multirow{6}{*}{2} & 1 & along the length & 388 & \multirow{6}{*}{397} \\
\hline & 2 & along the length & 397 & \\
\hline & 3 & along the length & 400 & \\
\hline & 4 & an angle of $90^{\circ}$ & 390 & \\
\hline & 5 & an angle of $90^{\circ}$ & 399 & \\
\hline & 6 & an angle of $90^{\circ}$ & 405 & \\
\hline \multirow{6}{*}{3} & 1 & along the length & 82 & \multirow{6}{*}{85} \\
\hline & 2 & along the length & 84 & \\
\hline & 3 & along the length & 88 & \\
\hline & 4 & an angle of $90^{\circ}$ & 81 & \\
\hline & 5 & an angle of $90^{\circ}$ & 86 & \\
\hline & 6 & an angle of $90^{\circ}$ & 88 & \\
\hline \multirow{6}{*}{4} & 1 & along the length & 89 & \multirow{6}{*}{92} \\
\hline & 2 & along the length & 92 & \\
\hline & 3 & along the length & 94 & \\
\hline & 4 & an angle of $90^{\circ}$ & 90 & \\
\hline & 5 & an angle of $90^{\circ}$ & 91 & \\
\hline & 6 & an angle of $90^{\circ}$ & 93 & \\
\hline \multirow{6}{*}{5} & 1 & along the length & 92 & \multirow{6}{*}{94} \\
\hline & 2 & along the length & 94 & \\
\hline & 3 & along the length & 95 & \\
\hline & 4 & an angle of $90^{\circ}$ & 92 & \\
\hline & 5 & an angle of $90^{\circ}$ & 95 & \\
\hline & 6 & an angle of $90^{\circ}$ & 96 & \\
\hline \multirow{6}{*}{6} & 1 & along the length & 155 & \multirow{6}{*}{160} \\
\hline & 2 & along the length & 160 & \\
\hline & 3 & along the length & 163 & \\
\hline & 4 & an angle of $90^{\circ}$ & 158 & \\
\hline & 5 & an angle of $90^{\circ}$ & 159 & \\
\hline & 6 & an angle of $90^{\circ}$ & 165 & \\
\hline
\end{tabular}

The test showed that the vertical displacement (h) in the vinyl ester resin matrix composites was less than in the polymer matrix resin composites (Figure 6). The vertical displacement is an indicator of flexural deformation and therefore, with more plastic materials, it will have a higher value, which explains the higher bending strength of the vinyl ester resin matrix composites. Here it has to be specified that a great impact on the matrix properties is imposed not only by the type of resin but also by the hardener used. Some brands of hardeners cause an increase in the plastic properties of the hardened resin and a decrease in its mechanical properties. This fact is confirmed by some experiments, which will be the subject of further research.

As regards the type of reinforcing phase, in the bending tests, the monoaxial fiberglass reinforced composites showed the highest bending strength (260-400 MPa) in both types of the matrix regardless of the angle of orientation of the fibers of the reinforcing phase. The PMC reinforced with triaxial fiberglass fabric, and particularly biaxial fiberglass fabric, are feature a significantly lower bending strength.

\section{Conclusion}

After the comparative analysis conducted, based on the results obtained we can conclude that for all the Fiber Reinforced PMC studied, vinyl ester resin used as a matrix material showed better mechanical strength properties than polyester resin, especially regarding of bending strength. The reinforcement phase has a significantly greater impact on the mechanical properties, with the monoaxial fiberglass reinforced PMC featuring the highest mechanical characteristics, irrespective of the matrix material. The highest tensile and flexural strengths are registered for monoaxial fiberglass reinforced PMC, followed by triaxial fiberglass reinforced PMC. The lowest mechanical strength characteristics are associated with biaxial fiberglass reinforced PMC, but related to the highest vertical displacement, i.e., they have higher plasticity.

Finally, we can conclude that all six types of composites are appropriate for the manufacturing of facilities operating in marine environments and tubular structures, and special attention is given to the load they will be subjected to. 


\section{References}

[1]. Bielawski, R., Kowalik, M., Suprynowicz, K., Rządkowski, W., \& Pyrzanowski, P. (2016). Investigation of riveted joints of fiberglass composite materials. Mechanics of Composite Materials, 52(2), 199-210.

[2]. Pipes from fiberglass: types, technical characteristics, prices (2018). Retrieved from:

https://srimathumitha.com/domashniy-uyut/15397truby-iz-stekloplastika-vidy-tehnicheskieharakteristiki-ceny.html [accessed: 19 April 2021].

[3]. Marin, T. I., \& Savov, B. (2017). Verification Of The Functional Efficiency Of Submerged Breakwaters By Field Measurements. Coastal Engineering Proceedings, (35), 18-18.

[4]. Verhagen, H. J., \& Savov, B. (2000, January). Sea Breeze Generated waves on the coast of Varna. In 2nd International Conference Port Development and Coastal Environment: PDCE 2000, 5-7 June 2000, Varna, Bulgaria. Black Sea Coastal Association.

[5]. Anastasiou C., Savov, B. (2020). Adapting to the Coastal Zone Challenges and Risks: Innovative Approaches and Solutions for Local and Regional Authorities in the Balkans-Mediterranean Region. HERMES Virtual International Conference, 43-48.

[6]. Azmi, A. I., Lin, R. J. T., \& Bhattacharyya, D. (2013). Machinability study of glass fibre-reinforced polymer composites during end milling. The International Journal of Advanced Manufacturing Technology, 64(1), 247-261.
[7]. Spasova, D., Argirov, Y., Mechkarova, T., \& Atanasov, N. (2021, February). Investigation of the suitability of fiber reinforced polymer matrix composites for facilities operating in marine environment. In IOP Conference Series: Materials Science and Engineering (Vol. 1037, No. 1, p. 012029). IOP Publishing.

[8]. Plastics - Determination of tensile properties - Part 5: Test conditions for unidirectional fibre-reinforced plastic composites (2009). Retrieved from: https://www.iso.org/standard/52991.html [accessed: July 2021].

[9]. Standard Test Method for Flexural Properties of Polymer Matrix Composite Materials (2021). Retrieved from: https://www.astm.org/Standards/D7264 [accessed: 01 March 2021].

[10]. Raheem, Z. (2020) Designation: D 7264/D 7264M 07 Standard Test Method for Flexural Properties of Polymer Matrix Composite Materials 1. Retrieved from: https://www.researchgate.net/publication/339947727 Designation D 7264D 7264M 07 Standard Test Method for_Flexural Properties of Polymer Matrix Composite Materials 1 [accessed: 20 March 2021]. 